\title{
HEAD AND NECK CANCER PATIENT PRIORITIES AND PREFERENCES FOR DISCUSSING AND RECEIVING INFORMATION ABOUT SEXUALITY FROM HEALTHCARE PROFESSIONALS
}

\section{Bethany A. Rhoten, PhD, RN | Vanderbilt School of Nursing \\ bethany.rhoten@vanderbilt.edu}

\section{BACKGROUND}

- Head and neck cancer and its treatment can cause significant disfigurement and functional decline

- Abilities critical to sexual function and sexual well-being are impacted: o neck movement

o facial expression

o saliva production

o breathing

o speech

o taste buds

o sense of smell

- Sexuality is an important quality of life issue for many patients.

\section{METHODOLOGY}

- Web-based, descriptive, cross-sectional design

- Recruitment via Cancer Center flyers, targeted emails, and online survivorship communities

- Responses collected via Research Electronic Data Capture (REDCap)

o Demographic and Clinical Characteristics

o Priority and Preference for Receiving Sexuality

Information Questionnaire

- Analysis using descriptive statistics: counts, percentages, measures of central tendency

\section{OBJECTIVE}

Examine the priorities and preferences of patients with head and neck cancer for discussing and receiving information about sexuality from healthcare professionals.

\section{RESULTS}

\begin{tabular}{|l|l|}
\hline Age $(\mathrm{n}=71)$ & \\
\hline mean, SD & 49.9 years, 15.1 years \\
\hline IQR 25-75 & $32-68.5$ years \\
\hline min, max & 23 years, 76 years \\
\hline Sex $(\mathrm{n}=73)$ & $\mathrm{n}(\%)$ \\
\hline Male & $38(52.1)$ \\
\hline Female & $34(46.6)$ \\
\hline Prefer not to respond & $1(1.4)$ \\
\hline Race ( $\mathrm{n}=73$ ) & \\
\hline White & $65(89.0)$ \\
\hline American Indian or Alaskan Native & $3(4.1)$ \\
\hline Black or African American & $3(4.1)$ \\
\hline Asian & $1(1.4)$ \\
\hline Native Hawaiian or Other Pacific Islander & $1(1.4)$ \\
\hline Ethnicity ( $\mathrm{n}=71)$ & \\
\hline Not Hispanic & $63(88.7)$ \\
\hline Hispanic & $8(11.3)$ \\
\hline Time since diagnosis $(\mathrm{n}=52)$ & \\
\hline Median, IQR 25-75 & 2.1 years, 1.0 years -7.3 years \\
\hline Min, max & 2.5 months -39.0 years \\
\hline
\end{tabular}

WHO would you prefer to speak with about sexual issues after head and neck cancer?
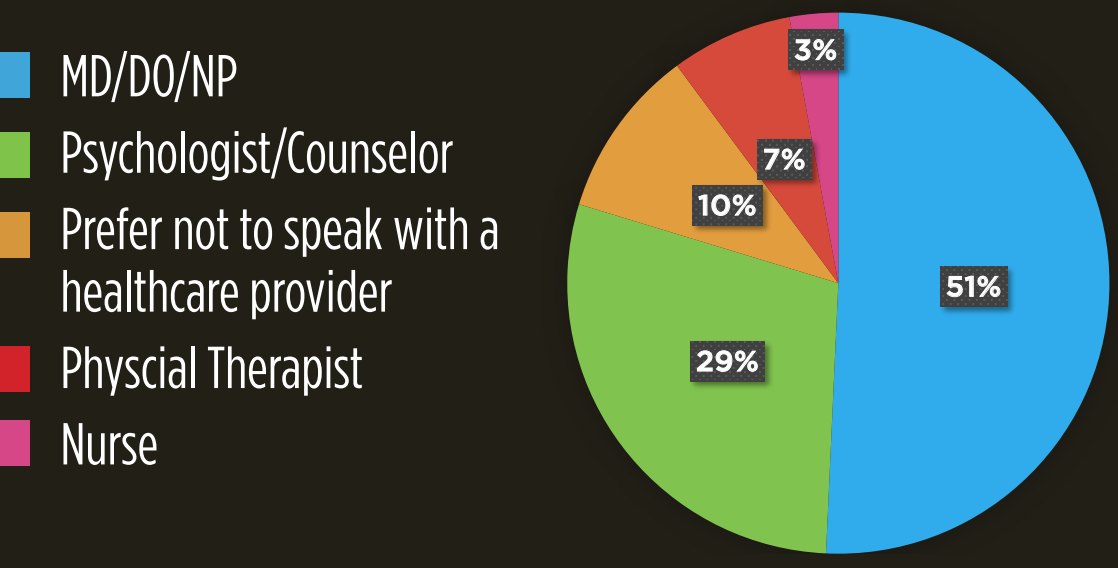

1st Choice $n=69$

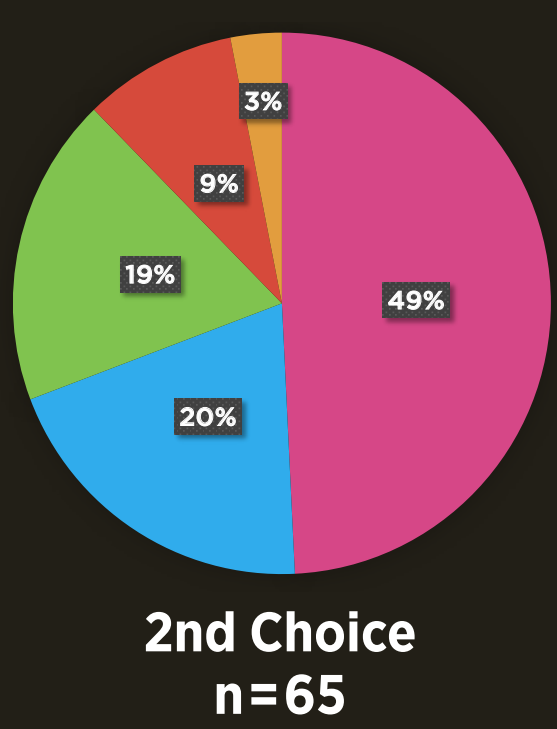

$n=65$
HOW would you prefer to receive information about sexual issues?

Discussion with healthcare
Printed material
Prefer not to receive
information
Digital format
Website

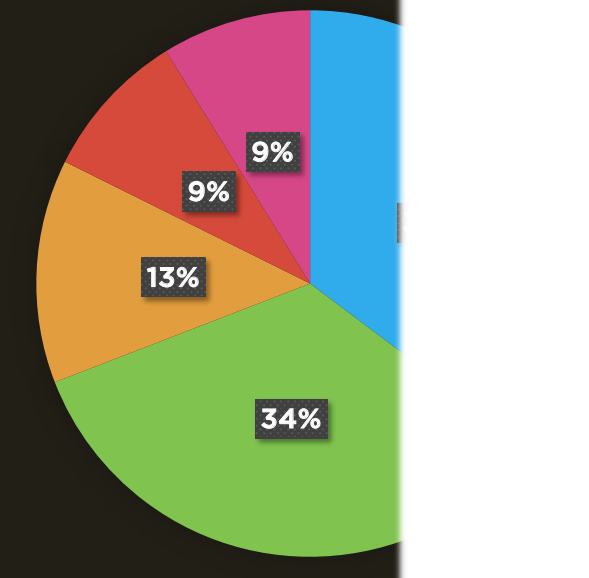

1st Choice

$n=68$

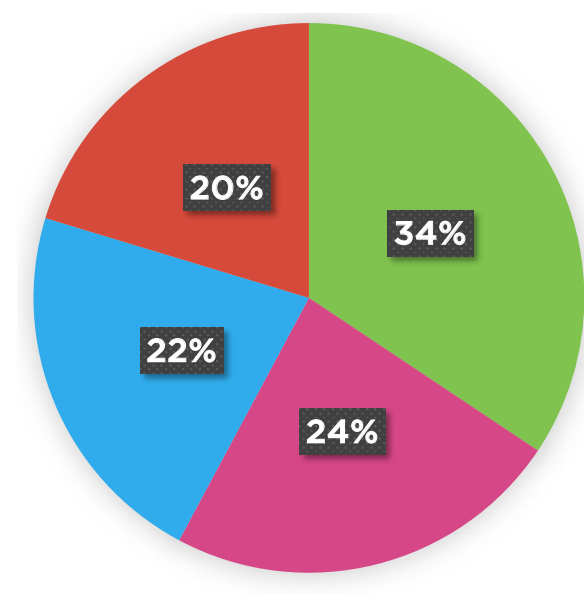

2nd Choice $n=64$

\section{$84 \%$ of participants indicated it was "Very Important" or "Somewhat Important" to receive information about sexual issues from their healthcare provider.}

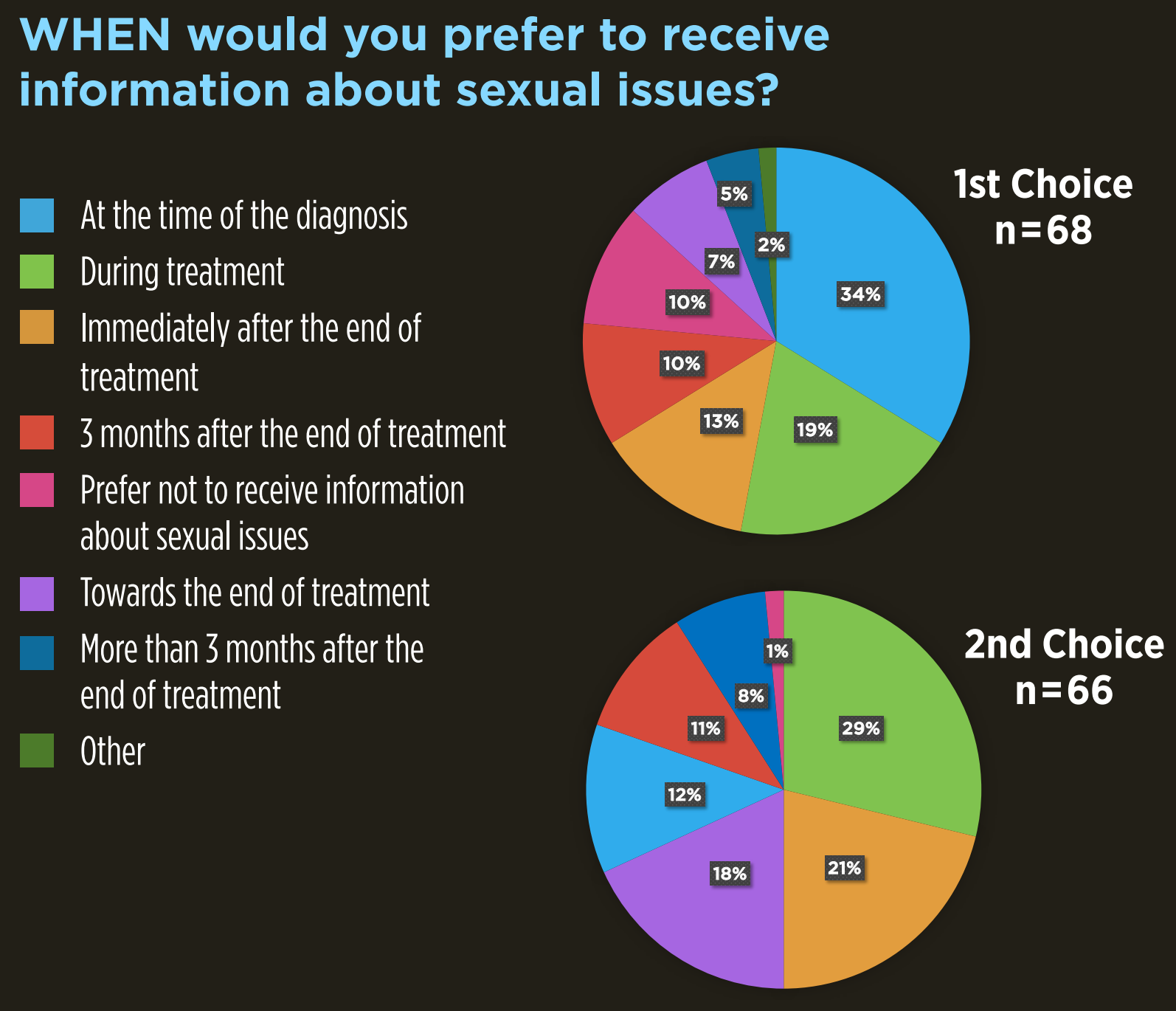

\section{CONCLUSION}

1. Patients with head and neck cancer overwhelmingly want to receive information about sexuality.

2. Patients want to receive this information from their healthcare providers, psychologists/counselors, and nurses. 3. Patients find discussions, printed material, websites, and other digital formats acceptable for receiving this information. do not necessarily represent official views of the funding agencies. 